\title{
Native versus invasive crab effluent effects on byssal thread production in the mussel, Mytilus trossulus (Gould, 1850)
}

\author{
Rachel Rickaby*, Jeanine Sinclair* \\ University of Victoria \\ rachel.rickaby@gmail.com, jeanine.sinclair3@gmail.com
}

\begin{abstract}
Mussels have evolved many adaptations to protect themselves, including the production of byssal threads. These are strong, proteinaceous fibres that mussels secrete to adhere themselves to rocks, preventing detachment by waves and predators. These byssal threads may be strengthened if mussels can recognize potential threats, such as native crabs, as their populations have a long history of coevolution. Unfortunately, the introduction of invasive predators poses a challenge for prey, which may not be capable of recognizing them. In this study, byssal thread production in the Pacific blue mussel (Mytilus trossulus) was observed when exposed to effluent from the native red rock crab (Cancer productus) or the invasive European Green crab (Carcinus maenas). M. trossulus were placed in closed systems with effluent from either C. productus, C. maenas or control (no predator), over a 24-hour time period. Final measurements of number, length and diameter of byssal threads were recorded. $M$. trossulus exposed to effluent from $C$. productus produced byssal threads at a statistically significantly faster rate than in the control group over the first 7.5 hours. $M$. trossulus exposed to effluent from C. maenas produced byssal threads at a statistically significantly faster rate than both the $C$. productus and control groups. However, after 24 hours, there was no statistically significant difference between the mean number of byssal threads for any treatment. Additionally, we found no statistically significant difference between the mean diameter of byssal threads produced or length of byssal threads produced for any treatment.

Keywords: Adaptive defense; Cancer productus; Carcinus maenas; Predator-induced defense; Phenotypic plasticity
\end{abstract}

$\mathrm{P}$ rey species have evolved many adaptations to protect themselves against predators. Through strong selective pressure, predators have profoundly influenced life history strategies, behavioural, physiological, and morphological defensive traits that are observed in extant prey species (Côté, 1995; Tollrian \& Harvell, 1999; Via \& Lande, 1985). However, permanent defensive structures are energetically costly, thus some anti-predator responses may only be initiated under reliable environmental stimuli (Brönmark et al., 2012; Tollrian \& Harvell, 1999; Via \& Lande, 1985). Phenotypically plastic traits can be induced so the most appropriate form of that trait is displayed for the exact conditions exerted on the prey (Carter, Lind, Dennis, Hentley, \& Beckerman, 2017; Côté, 1995; Lowen, Innes, \& Thompson, 2013; Via \& Lande, 1985). The co-evolution of predators and prey have helped facilitate phenotypically plastic traits to be induced when prey can accurately assess a predation risk, so energy is only spent on a defense when it is essential to survival (Reimer \& Tedengren, 1997; Tollrian \& Harvell, 1999; Via \& Lande, 1985). Unfortunately, the lack of

${ }^{*}$ The authors thank the Bamfield Marine Sciences Centre, for making this work possible. The authors would also like to thank Professor Tao Eastham, Professor Heather Alexander, Aaron Eger, Allan Roberts, Rylan Command, Beth Rogers, Maddy Walter, Siobhan Gray, Haley Robb, Sophia Kontou, Hailey Shafer, Mary Clinton, Olivia Walker, and their fellow Fall Program students for guidance and support. 
coevolution of prey species with invasive predators poses a threat, as prey rely on predator detection to prompt defenses (Freeman \& Byers, 2006).

Inducible defenses have evolved as a cost saving strategy, where resources are only allocated to a certain defensive trait if it directly aids in survival (Brönmark et al., 2012; Griffiths \& King, 1979; Kats \& Dill, 1998; Via \& Lande, 1985). Otherwise, these resources can be used in growth or reproduction (Brönmark et al., 2012; Via \& Lande, 1985). For many bivalves, induced anti-predator defenses include shell thickening, strengthening of the adductor muscles, and increasing byssal thread production when exposed to wave action, sea stars, and crabs, respectively (Caro, Escobar, Bozinovic, Navarrete, \& Castilla, 2008; Cheung, Tong, Yip, \& Shin, 2004; Freeman \& Byers, 2006; Reimer \& Tedengren, 1997). In mussels, byssal threads are a vital defensive mechanism used to hold onto a substrate and maintain their position in clumps, which decreases predation risk (Behrens Yamada \& Boulding, 1998; Côté \& Jelnikar, 1999; Elner, 1978). Reimer and Tedengren (1997) tested byssal thread production in the mussel Mytilus edulis (Linnaeus, 1758), and found that the mussels produced a strong byssal thread attachment when exposed to the sea star, Asterias rubens (Linnaeus, 1758) and the European green crab Carcinus maenas (Linnaeus, 1758), which is native to that region.

In the Northwest Atlantic, Côté (1995) studied M. edulis, and found that energy is directly reallocated from growth and reproduction into byssal thread production. Côté (1995) also demonstrated how effluent from a crab native to the area, Cancer pagurus (Linnaeus, 1758), increased the number of thicker byssal threads produced by their prey, M. edulis, compared to those with no predator or a non-threatening herbivore (Côté, 1995). However, no equivalent study to Côté's exists for the relationship between Mytilus trossulus (Gould, 1850), Cancer productus (Randall, 1840) and Carcinus maenas in the Pacific Northwest.

The blue mussel, M. trossulus, is commonly found in intertidal habitats along the Northeastern Pacific coast. As a foundation species, M. trossulus beds provide vital habitat and shelter from predation to over 300 intertidal species (Lafferty \& Suchanek, 2016). These fundamental aggregations promote biodiversity along the coastlines and are therefore a very important west coast species to research (Lafferty \& Suchanek, 2016). The distribution of the native mussel, M. trossulus, overlaps with that of their predator, Cancer productus, the native crab species (Braby \& Somero, 2006; Carroll \& Winn, 1989).

The invasive European green crab, C. maenas, thrives outside its natural range due to its lack of predator and high tolerance to fluctuating environmental conditions (Behrens Yamada \& Gillespie, 2008; Carlton \& Cohen, 2003; Leignel, Stillman, Baringou, Thabet, \& Metais, 2014). A strong cohort of this species was first detected on the Pacific coast in San Francisco Bay in 1989 and most likely dispersed north to Barkley Sound during the 1997/1998 El Niño episode (Behrens Yamada \& Gillespie, 2008). The invasive C. maenas have established breeding populations in parts of Barkley Sound, such as Useless Inlet and Pipestem Inlet. Certain populations of C. maenas have been found to overlap with the native M. trossulus (Braby \& Somero, 2006; Carlton \& Cohen, 2003). Both crab species forage on $M$. trossulus during high tides, where they cut the mussels off the rock and use their powerful chelae to crush their hard shells (Behrens Yamada \& Boulding, 1998; Carroll \& Winn, 1989).

Research conducted on Prince Edward Island, Canada found evidence to suggest that the invasive C. maenas may threaten commercially important bivalves such as M. edulis as well as compete with a native rock crab, Cancer irroratus (Miron, Audet, Landry, \& Moriyasu, 2005). In central California, it was found that European green crabs were causing massive declines in the population of the native clams, Nutricola spp., as well as the local shore crab, Hemigrapsus oregonensis (Grosholz, 2002). Grosholz (2002) indicated that C. maenas can alter the structure of the native rocky shoreline communities in areas of low water flow by predating on mussels. In New England, native periwinkle 
snails, Littorina obtusata, were observed for their varying degrees of phenotypic plasticity when exposed to the introduced C. maenas (Trussel \& Smith, 2000). They found that the degree of induced defense they displayed was largely based on their previous experience with exposure to the C. maenas (Trussel \& Smith, 2000). These results may allude to a potential situation occurring on the Western coast of Canada, with the native C. productus and the same invasive C. maenas. In this study, the native species, $M$. trossulus and $C$. productus, are highly influential in their respective ecosystems, and the invasive C. maenas has been observed to have negative effects on similar prey and competing species.

Unfortunately, the lack of evolutionary history between an introduced predator and native prey, such as $C$. maenas and M. trossulus, often gives no opportunity for adaptive defensive traits to evolve against the threat (Freeman \& Byers, 2006). This can leave prey vulnerable to attack if they depend on induced traits where chemical effluents are a signal of a predator threat (Freeman \& Byers, 2006). If $M$. trossulus display changes in byssal thread production in the presence of the native $C$. productus effluent, this could indicate an adaptive response due to frequent predator-prey interactions over evolutionary time. If $M$. trossulus do not display any changes when exposed to the invasive $C$. maenas, this may indicate an inability for prey to respond to novel invasive predators, leaving them susceptible to predation.

In this study, we experimentally determined whether M. trossulus sampled from Bamfield Inlet, B.C., increased their byssal thread number, length, and thickness when exposed to the native red rock crab, C. productus. We compared this response to the invasive European green crab, C. maenas, a relatively recent recruit to Barkley Sound. We hypothesized that 1 . effluent from the native crab would induce an overall higher number of byssal threads in mussels than the invasive crab or control; 2. the byssal threads produced in the presence of the native crab would be thicker and shorter than the control or the invasive predator treatments; 3 . and the invasive predator treatment would not induce significantly different byssal thread production from the control.

\section{Materials and Methods}

\section{Collection of Study Species}

The two native species, C. productus and M. trossulus, were both collected from the Bamfield Inlet, B.C., Canada $\left(48^{\circ} 50^{\prime} 3.9^{\prime \prime} \mathrm{N}, 125^{\circ} 8^{\prime} 13.1^{\prime \prime} \mathrm{W}\right)$ where their habitats naturally overlap in the protected intertidal, in early November, 2018. However, C. maenas were collected from two separate sites, both over $20 \mathrm{~km}$ away from Bamfield Inlet (Fig 1). Three C. maenas were collected from Useless Inlet $\left(48^{\circ} 59^{\prime} 22.7^{\prime \prime} \mathrm{N}, 125^{\circ} 3^{\prime} 16.2^{\prime \prime} \mathrm{W}\right)$ and seven $C$. maenas were collected from Pipestem Inlet $\left(49^{\circ} 1^{\prime} 35.2^{\prime \prime} \mathrm{N}, 125^{\circ} 15^{\prime} 36.1^{\prime \prime} \mathrm{W}\right)$ in October and November, 2018. C. productus and C. maenas were transported back to the Bamfield Marine Sciences Centre, housed in separate sea tables with flowing seawater, and fed mussels twice weekly, one month prior to the experiment.

Mussels were carefully removed from rocks by cutting their byssal threads nearest to the substrate, to avoid damaging the pedal apparatus and altering byssal thread production. Mussels were kept together in containers with flowing seawater for one month prior to the start of the experiment. All mussels held in the lab were fed a cumulative 1 tsp of algae paste (Innovative Aquaculture Products LTD) suspended in seawater, 24 hours before each trial began.

\section{Experimental Setup}

Experimental design and measurement of byssal threads were adapted from Côté (1995). The three treatments were as follows: The invasive treatment contained a single male $C$. maenas in 
a plastic container with drilled holes on all four sides, which was placed into a larger plastic bin. The bin and container were filled three quarters full of seawater before shutting off water flow and replacing it with an airstone in the now closed system. Crabs were not fed during the trial, to avoid chemical cues from injured conspecifics influencing results. The native treatment was the same setup, except a single male $C$. productus was placed in the container. For the control, all conditions were identical, excluding the crab in the container.

Each container and bin setup represented one experimental unit. Crabs were placed into each unit 12 hours before mussels were added, to allow effluent to accumulate and flow evenly throughout each bin. Four sea tables held six experimental units each, and a fifth sea table contained three units, resulting in nine replicates of each treatment $(N=9)$ for a total of 27 experimental units. Each table held two replicates of each treatment (except table five which only had one of each treatment), and all experimental units were randomly assigned positions within the table (Fig 2).

Approximately 30 minutes before adding mussels to the experimental units, mussels were prepared by carefully cutting all byssal threads off as close to the byssal stem as possible and without damaging the pedal apparatus. Mussel shell length was measured using Vernier calipers to the nearest 0.05 $\mathrm{mm}$ (specimen length). All mussels were randomly assigned individual specimen IDs that identified treatment type and bin number. Mussels were placed into individual plastic petri dishes and put into their corresponding experimental unit.

\section{Byssal Thread Counts}

The number of threads secreted by all mussels were counted by observing through the base of the petri dish. Threads were counted after 30 minutes of exposure to their closed treatments, one hour after that, and then each subsequent hour after, until 7.5 hours elapsed from the start of the experiment. After 24 hours, all mussels were removed from their experimental units and a final byssal thread count was taken. Any mussels that produced 0 threads during the 24 hour period were eliminated from analysis. One mussel from each experimental unit was then randomly selected using a random number generator for further byssal thread measurements.

\section{Measuring Byssal Thread Length and Diameter}

The selected mussel from each experimental unit was used to determine average byssal thread length $(\mu \mathrm{m})$ and diameter $(\mathrm{mm})$. To determine the average length for each individual mussel, three byssal threads (longest, shortest, and one randomly selected) were measured to the nearest $0.05 \mathrm{~mm}$ with a Vernier caliper. Any threads that could be removed were set aside and used to determine average byssal thread diameter. This was measured using an ocular micrometer on a compound microscope (Olympus CX31). Individual threads were taped lengthwise to a microscope slide and the maximum diameter $(\mathrm{mm})$ was recorded at the maximum width.

\section{Statistical Analyses}

We used a linear model to test for a relationship between the number of byssal threads secreted and time, while also asking if this relationship was different between the treatments. To analyze the differences between the rates in each treatment, we performed an ANCOVA. We used a linear model to test for differences between the number of byssal threads secreted after 24 hours in each treatment and this was analyzed using ANOVA. To test for differences in byssal thread diameter by treatment, a linear model was used and analyzed using ANOVA. To test for differences in byssal thread length between the two treatments, we used a generalized linear model with a gamma distribution to account for non-normality. ANOVA was then used to analyze the differences. Because the length of 
The Arbutus Review • $2018 \bullet$ Vol. 9, No. $1 \bullet$ https://doi.org/10.18357/tar91201818384

the mussel influenced the secretion rate and length of byssal threads produced, we accounted for the length of each individual mussel in the models. We determined a result to be statistically significant if the $p$-value was less than 0.05. All analyses were conducted in the $\mathrm{R}$ programming environment 3.4.1 (R Core Team, 2017), and the package ggplot2 (Wickham, 2009) was used.

\section{Results}

\section{Number of Byssal Threads}

The rate of byssal thread secretion over the first 7.5 hours of the experiment was highest in the invasive crab, C. maenas, treatment, second highest in the native crab, C. productus, treatment, and lowest in the control treatment (Fig 3A). Using ANCOVA, we found that the invasive crab treatment had a statistically significantly higher average secretion rate than the control, with an average of 0.029 more byssal threads produced per mm of individual mussel length $\left(p=10^{-6}\right)$. The invasive crab, $C$. maenas, treatment also had a statistically significantly higher average secretion rate than the native crab treatment with an average of 0.014 more byssal threads produced per $\mathrm{mm}$ of individual mussel length $\left(p=5.63 \times 10^{-4}\right)$. The native crab treatment also had a statistically significantly higher average secretion rate than the control, with an average of 0.014 more byssal threads produced per mm of individual mussel length $\left(p=5.60 \times 10^{-4}\right)$.

After 24 hours, $M$. trossulus in the control, native, and invasive treatments had produced an average number of byssal threads of $8.64 \pm 3.85,10.72 \pm 4.04$, and $9.87 \pm 3.31$, respectively (Fig 3B). Using ANOVA, we found no difference between the mean number of byssal threads for any treatment $(F=1.82, d f=26, p=0.184)$.

\section{Diameter of Byssal Threads}

Byssal threads produced in control, native, and invasive treatments had average diameters of $0.33 \pm 0.07 \mu \mathrm{m}, 0.45 \pm 0.14 \mu \mathrm{m}$, and $0.41 \pm 0.11 \mu \mathrm{m}$, respectively (Fig 4). Unlike the number and length of threads produced, the length of the individual mussel did not influence the diameter of byssal threads produced. Using ANOVA, we found no difference between the mean diameter of byssal threads for any treatment $(F=2.72, d f=26, p=0.086)$.

\section{Length of Byssal Threads}

Byssal threads produced in control, native, and invasive treatments had average lengths of $11.31 \pm 3.56 \mathrm{~mm}, 9.47 \pm 2.82 \mathrm{~mm}$, and $9.62 \pm 3.00 \mathrm{~mm}$, respectively (Fig 5). Using ANOVA, we found no difference between the mean length of byssal threads for any treatment $(F=0.95, d f=$ $26, p=0.402)$.

\section{Discussion}

The aim of this study was to observe the difference in byssal thread production in $M$. trossulus when exposed to two different predators, the native red rock crab, C. productus, and the invasive European green crab, C. maenas. This study demonstrates how M. trossulus increases byssal thread secretion rate when exposed to effluent from both the native predator, $C$. productus, and the invasive predator, C. maenas. This is the first time that byssal thread production of $M$. trossulus has been investigated comparing $C$. productus and C. maenas from the Northwest Pacific coast.

Previous research by Côté (1995) investigated byssal thread production in a related mussel species, M. edulis, and a related crab species, Cancer pagurus, on the North Atlantic east coast. 
Côté (1995) found that M. edulis produced more byssal threads that were shorter and thicker when exposed to predator effluent. These differences were evident after 6 hours but after 22 hours had no statistically significant differences between treatments. Our experiment showed similar results: The rates of byssal thread secretion over the first 7.5 hours were statistically significantly higher than the control for both predator treatment, but after 24 hours there was no statistically significant difference in the number of threads present. Contrary to Côté (1995), we found no statistically significant differences in byssal thread length or diameter between treatments.

The number of byssal threads secreted over time (secretion rate) was statistically significantly higher for the native $C$. productus treatment, in comparison to the control. The secretion rate for the invasive C. maenas treatment was also statistically significantly higher than the control. However, the secretion rate was highest in the invasive treatment, with a statistically significantly higher rate than the native treatment, which was unexpected. Additionally, M. trossulus specimen length had a positive relationship with secretion rate; secretion rate increased with increasing specimen length.

These results suggest that $M$. trossulus were able to recognize effluent from both $C$. productus and C. maenas, and increase the number of byssal threads produced. While we expected this response from $M$. trossulus in the presence of $C$. productus, we did not anticipate the same response in the $C$. maenas treatments. The response seen in the $C$. productus treatment is likely due to $M$. trossulus and C. productus populations co-evolving over a long period of time, where chemosensory abilities were selectively favoured over other anti-predator defenses (Kats \& Dill, 1998). It is possible that through co-evolution and adaptive traits, M. trossulus are able to detect the pheromones and excretory products from C. productus as water-borne chemical cues, as this has been found for similar mussel species (Côté, 1995; Kats \& Dill, 1998). However, it is possible that many crabs elicit similar water-borne cues and $M$. trossulus are therefore able to detect many crab predators, such as C. maenas. Furthermore, perhaps $M$. trossulus has been in contact with $C$. maenas long enough for evolutionary change to occur in the mussel population. Nunes, Orizaola, Laurila, and Rebelo (2014) found that an invasive crayfish imposed strong predation pressure on its prey, resulting in rapid evolutionary shifts for the invaded populations. As C. maenas is a voracious predatory invader, it could likely impose a similar strong predation pressure. This potential evolutionary shift could explain why $M$. trossulus seem adapted to the invader and why they produced an even higher byssal thread secretion rate in the presence of $C$. maenas compared to C. productus.

The increased secretion rate in these treatments is most likely $M$. trossulus attempting to secure themselves to the substrate with as many threads as possible for stronger attachment. Mussels aggregate in tightly packed clumps and have been observed to aggregate under risk of predation in a laboratory setting (Côté \& Jelnikar, 1999). Many predacious crabs hunt along the edges and the top of mussel beds, where exposed mussels are more vulnerable to their byssal threads being cut (Côté \& Jelnikar, 1999). The increase in byssal thread production of all individuals upon detection of a predator could benefit the group by increased attachment to each other and the substrate, reducing the threat of predation by detachment (Côté \& Jelnikar, 1999).

After 24 hours, there were no statistically significant differences between the number of byssal threads present for any combination of treatments. According to Côté (1995), this could be due to energetic cost, as byssal thread production uses a considerable amount of the nitrogen and carbon budgets that are normally allocated to growth. Additionally, Griffiths and King (1979) found that there is a direct trade-off between growth and byssal thread production. Therefore, a long-term increased rate of byssal thread secretion may not be feasible. Furthermore, after 24 hours of exposure to a predatory crab, the mussel would have either been preyed upon or left alone by the respective predator. The 24 hour period is therefore considered a good measure of whether the mussel would have survived or been eaten with the induced defenses it may or may not have produced.

Byssal thread diameters and lengths were not statistically significantly different between any of 
the three treatments. This may be due to the $M$. trossulus allocating more resources to producing a greater overall amount of byssal threads in the presence of a predatory crab, rather than making those byssal threads thicker in diameter or shorter. Although Côté (1995) found a statistically significant decrease in length and increase in diameter of Atlantic $M$. edulis byssal threads when exposed to C. pagurus, the Pacific M. trossulus mussels do not appear to show these same changes.

Nonetheless, there was a clear trend seen in Fig 4, that byssal threads in the native treatment were, on average, thicker than byssal thread produced in the control groups. This trend may have become significant if we had a higher sample size. The larger diameter seen in the native treatment may be due to byssal threads being stronger when they are thicker, thus reducing detachment by predators (Côté, 1995).

The introduction of C. maenas is just one example of anthropogenic transport of invasive species to novel communities (Carlton \& Cohen, 2003; Freeman \& Byers, 2006). Novel introductions bring organisms with no shared evolutionary history, where predators have an advantage over prey relying on chemical cues from the local predators (Cox, 2004; Freeman \& Byers, 2006). If prey cannot recognize new predators as a threat, they will be unable to generate the appropriate defense mechanism and will be left vulnerable (Freeman \& Byers, 2006). As an abundant species in the Pacific Northwest, M. trossulus is fundamental for providing shelter to many organisms and supporting intertidal biodiversity (Lafferty \& Suchanek, 2016). Our results show that $M$. trossulus may be capable of defending against this voracious predator, which is promising. These essential aggregations of mussels could promote further expansion of C. maenas by providing an easy food source if their populations experience constant increased predation (Lafferty \& Suchanek, 2016).

Most effective predator recognition by prey occurs when the prey and predator share common evolutionary history (Nunes et al., 2014; Strauss, Lau, \& Carroll, 2006). The native crab, C. productus, has had an overlapping distribution with their prey, M. trossulus, for a long period of time (Freeman \& Byers, 2006). Therefore, it is logical that $C$. productus elicits a defensive response in M. trossulus. Invader-driven rapid evolutionary change is rare, so developing a defense response to predation by an invader may take many generations (Cox, 2004; Freeman \& Byers, 2006). However, as shown by Nunes et al. (2014), a rapid evolutionary shift in a prey population is possible. This is particularly true when the invader provides constant and intense predation (Nunes, et al., 2014; Strauss et al., 2006). We suggest two possibilities for why C. maenas induced an increased rate of byssal thread secretion: 1. M. trossulus recognizes a general water-borne chemical cue, similar to many crab species. 2. Rapid evolutionary changes have occured in M. trossulus as a result of strong selective pressure imposed by C. maenas.

Future research should investigate the rate of byssal thread secretion on more natural substrates, as our study was limited to secretion on plastic. In the intertidal zone, $M$. trossulus frequently lays down byssal threads on rock and other mussels, so replicating this may cause increased rates of thread secretion (Côté \& Jelnikar, 1999). It may also be beneficial to monitor the byssal thread secretion rate for longer than the first 7.5 hours, to see how the rates change between 7.5 and 24 hours. Additional research should investigate $M$. trossulus populations that overlap with both $C$. productus and $C$. maenas and compare results to $M$. trossulus populations that have never been exposed to $C$. maenas. This will test if $M$. trossulus can evolve an induced response in byssal thread production in the presence of $C$. maenas effluent. 


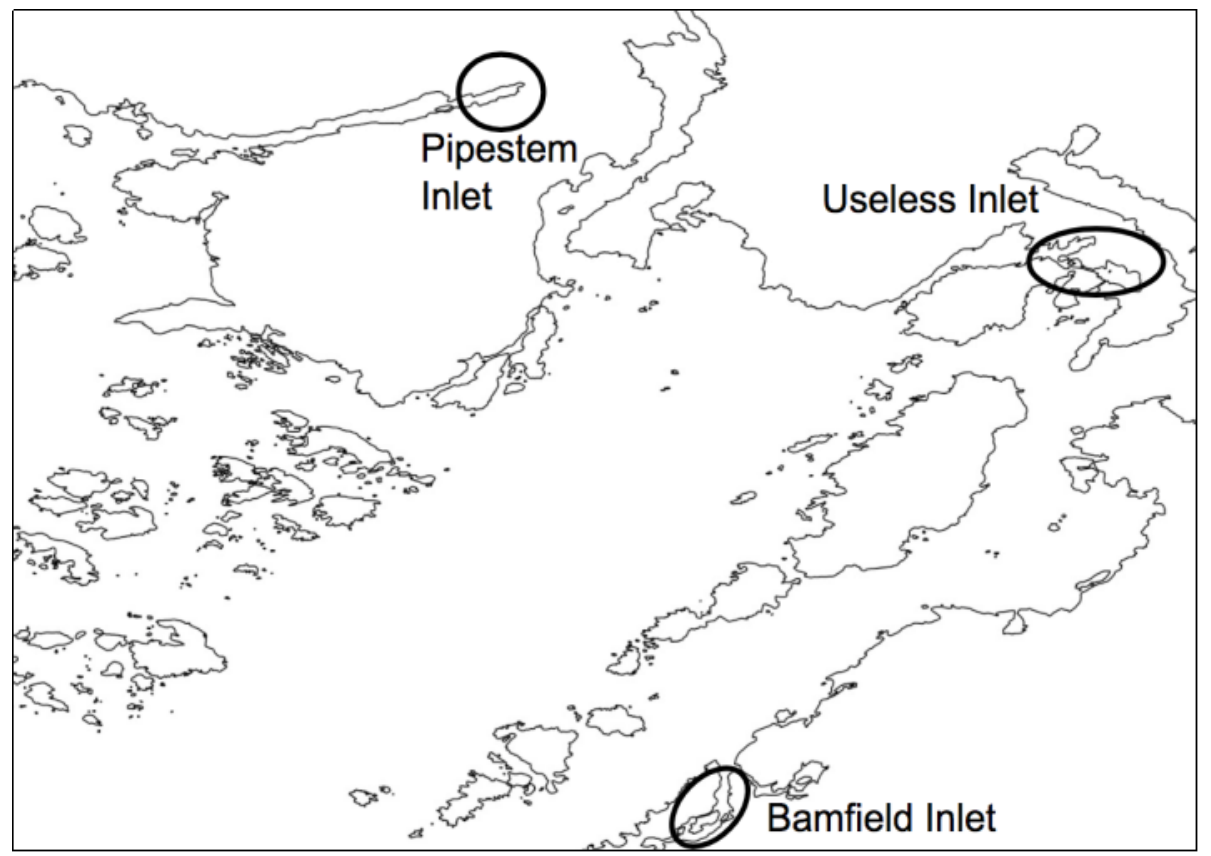

Figure 1: Map of collections sites; Bamfield Inlet $\left(48^{\circ} 50^{\prime} 3.9^{\prime \prime} N, 125^{\circ} 8^{\prime} 13.1^{\prime \prime}\right.$ W), Useless Inlet $\left(48^{\circ} 59^{\prime} 22.7^{\prime \prime}\right.$ $N, 125^{\circ} 3^{\prime} 16.2^{\prime \prime} W$ ), and Pipestem Inlet $\left(49^{\circ} 1^{\prime} 35.2^{\prime \prime} N, 125^{\circ} 15^{\prime} 36.1^{\prime \prime} W\right)$. Mytilus trossulus and Cancer productus were collected from Bamfield Inlet. Carcinus maenas were collected from either Useless Inlet or Pipestem Inlet.

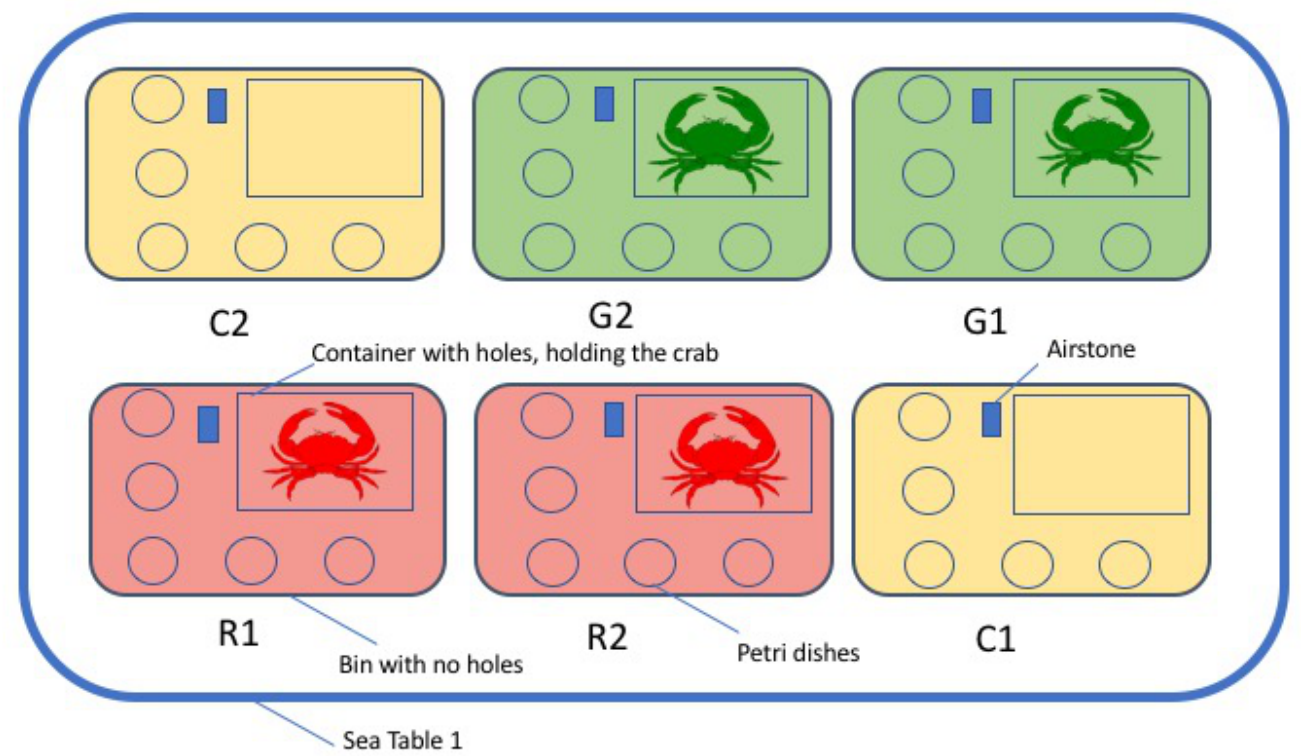

Figure 2: Experimental design of Sea Table 1. Container has holes to allow for water flow, and a lid to contain the predator. The bin was approximately three quarters full with an air stone and no water flow. Five petri dishes were placed in each bin, each with one individual of Mytilus trossulus. All individuals of M. trossulus had markings to ID to bin and treatment numbers. 

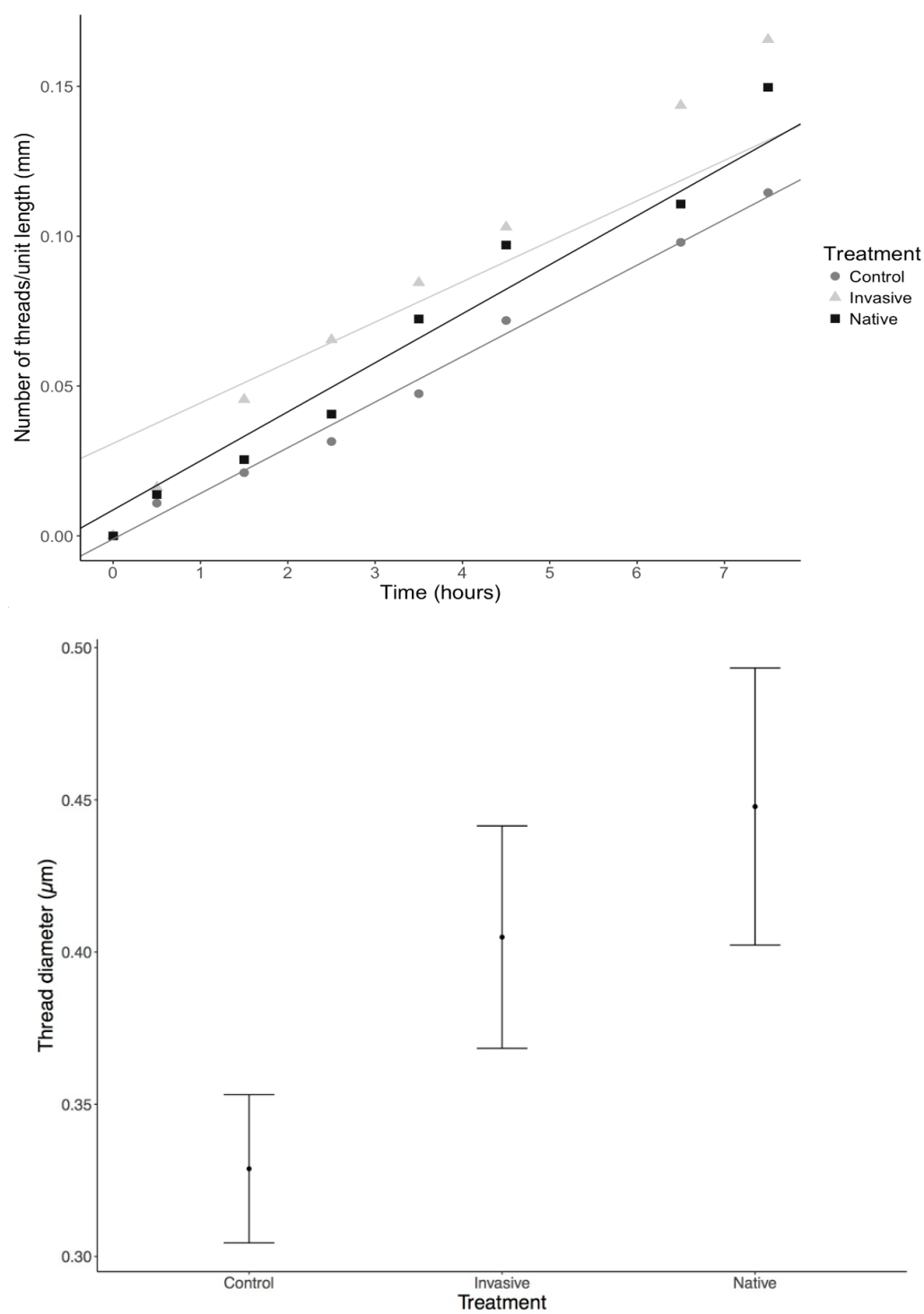

Figure 3: Top: Average rate of thread secretion of Mytilus trossulus in each treatment over a period of 7.5 hours. There was a positive correlation between specimen length and secretion rate $(p<0.001)$, so secretion rate was standardized by taking the average number of byssal threads produced per length of individual. Bottom: Average number of byssal threads secreted by Mytilus trossulus in each treatment after 24 hours. Error bars represent standard error. 


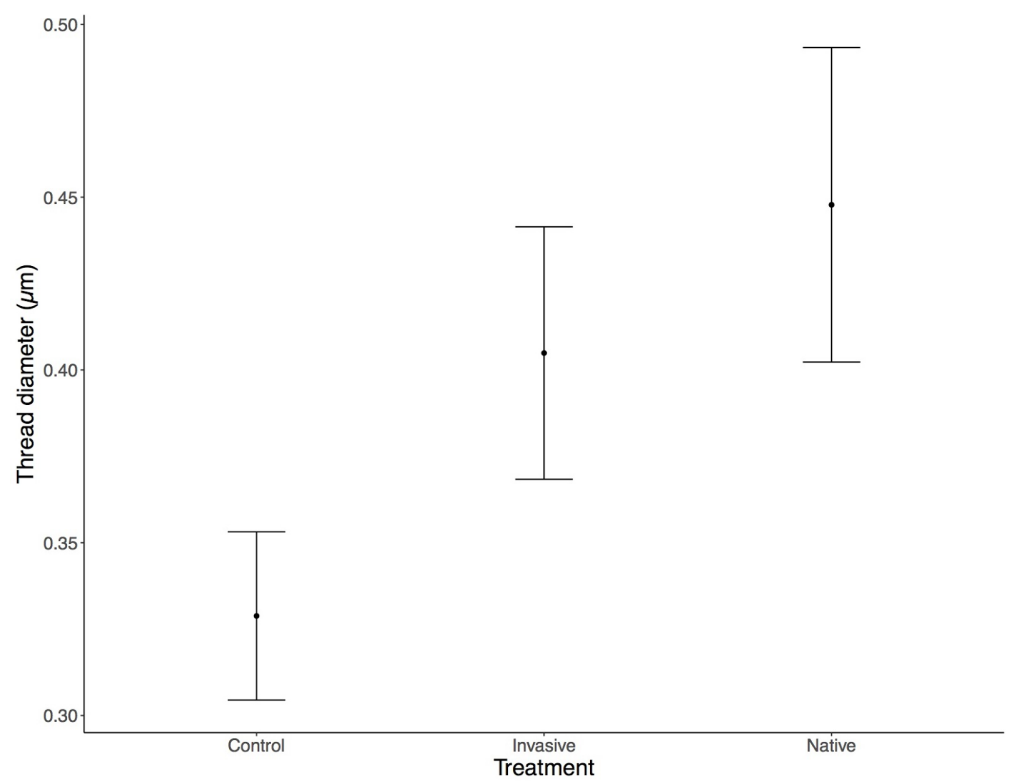

Figure 4: Average diameter of byssal threads secreted by Mytilus trossulus in each treatment after 24 hours. Error bars represent standard error.

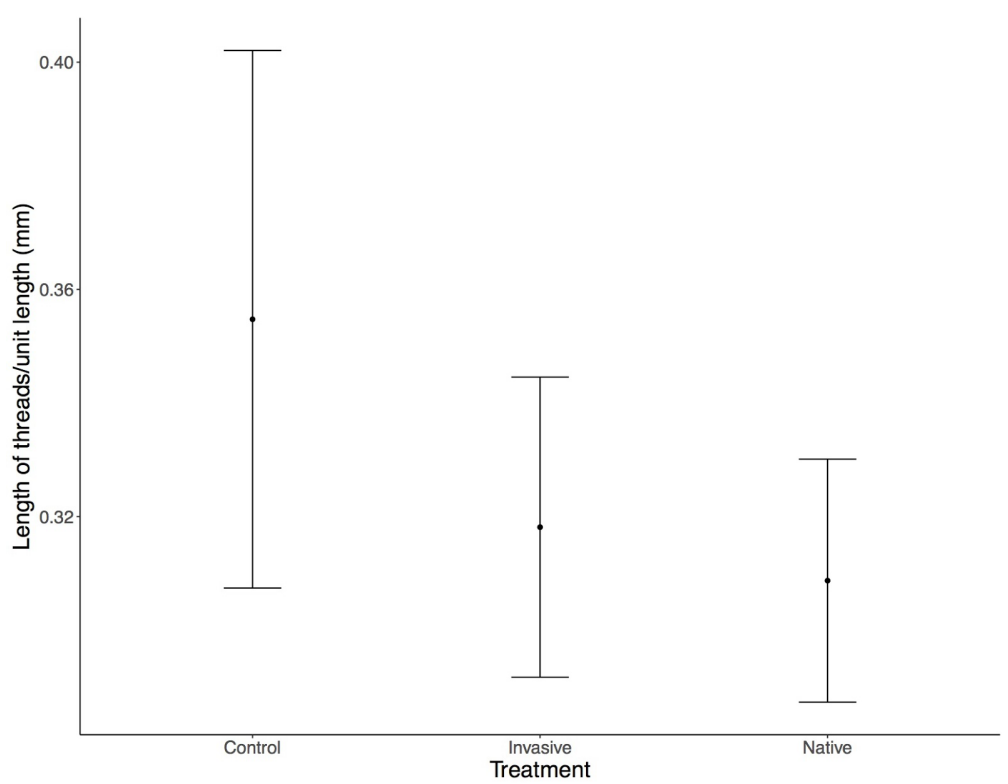

Figure 5: Average length of byssal threads produced by Mytilus trossulus in each treatment over a period of 24 hours. There was a positive correlation between specimen length and secretion rate $(p=0.026)$, so byssal length was standardized by taking the average length of thread produced per length of individual. Error bars represent standard error. 
The Arbutus Review • $2018 \bullet$ Vol. 9, No. $1 \bullet$ https://doi.org/10.18357/tar91201818384

\section{References}

Behrens Yamada, S., \& Boulding, E. G. (1998). Claw morphology, prey size selection and foraging efficiency in generalist and specialist shell-breaking crabs. Journal of Experimental Marine Biology and Ecology, 220(2), 191-211. https://doi.org/10.1016/S0022-0981(97)00122-6

Behrens Yamada, S., \& Gillespie, G. E. (2008). Will the European green crab (Carcinus maenas) persist in the Pacific Northwest? ICES Journal of Marine Science, 65(5), 725-729. https://doi.org/10.1093/icesjms/fsm191

Braby, C. E., \& Somero, G. N. (2006). Ecological gradients and relative abundance of native (Mytilus trossulus) and invasive (Mytilus galloprovincialis) blue mussels in the California hybrid zone. Marine Biology, 148(6), 1249-1262. https://doi.org/10.1007/s00227-005-0177-0

Brönmark, C., Lakowitz, T., Nilsson, P. A., Ahlgren, J., Lennartsdotter, C., \& Hollander, J. (2012). Costs of inducible defence along a resource gradient. PLoS ONE, 7(1), e30467. https://doi.org/10.1371/journal.pone.0030467

Carlton, J. T., \& Cohen, A. N. (2003). Episodic global dispersal in shallow water marine organisms: The case history of the European shore crabs Carcinus maenas and C. aestuarii. Journal of Biogeography, 30(12), 1809-1820. https://doi.org/10.1111/j.1365-2699.2003.00962.x

Caro, A. U., Escobar, J., Bozinovic, F., Navarrete, S. A., \& Castilla, J. C. (2008). Phenotypic variability in byssus thread production of intertidal mussels induced by predators with different feeding strategies. Marine Ecology Progress Series, 372, 127-134. https://doi.org/10.3354/meps07701

Carroll, J. C., \& Winn, R. N. (1989). Species profiles. Life histories and environmental requirements of coastal fishes and invertebrates (Pacific Southwest). Brown Rock Crab, Red Rock Crab, and Yellow Crab. U.S. Fish Wildl. Serv. Biol. Rep., 82(11.117).

Carter, M. J., Lind, M. I., Dennis, S. R., Hentley, W., \& Beckerman, A. P. (2017). Evolution of a predator-induced, nonlinear reaction norm. Proceedings. Biological Sciences, 284(1861). https://doi.org/10.1098/rspb.2017.0859

Cheung, S. G., Tong, P. Y., Yip, K. M., \& Shin, P. K. S. (2004). Chemical cues from predators and damaged conspecifics affect byssus production in the green-lipped mussel Perna viridis. Marine and Freshwater Behaviour and Physiology, 37(2), 127-135. https://doi.org/10.1080/102362404. 10001705798

Côté, I. M. (1995). Effects of predatory crab effluent on byssus production in mussels. Journal of Experimental Marine Biology and Ecology, 188(2), 233-241. https://doi.org/10.1016/00220981(94)00197-L

Côté, I. M., \& Jelnikar, E. (1999). Predator-induced clumping behaviour in mussels (Mytilus edulis Linnaeus). Journal of Experimental Marine Biology and Ecology, 235(2), 201-211. https://doi.org/10.1016/S0022-0981(98)00155-5

Cox, W. G. (2004). Alien species and evolution: The evolutionary ecology of exotic plants, animals, microbes and interacting native species. Washington, DC: Island Press. https://doi.org/10.5811/westjem.2011.5.6700

Elner, R. W. (1978). The mechanics of predation by the shore crab, Carcinus maenas (L.), on the edible mussel, Mytilus edulis L. Oecologia, 36 (3), 333-344. https://doi.org/10.1007/BF00348059

Freeman, A. S., \& Byers, J. E. (2006). Divergent induced responses to an invasive predator in marine mussel populations. Science (New York, N.Y.), 313(5788), 831-3. https://doi.org/10.1126/science.1125485

Griffiths, C. L., \& King, J. A. (1979). Energy expended on growth and gonad output in the ribbed mussel Aulacomya ater. Marine Biology, 53(3), 217222. https://doi.org/10.1007/BF00952429

Grosholz, E. (2002). Ecological and evolutionary consequences of coastal invasions. Trends in Ecology \& Evolution, 17(1), 22-27. 
Kats, L. B., \& Dill, L. M. (1998). The scent of death: Chemosensory assessment of predation risk by prey animals. Écoscience, 5(3), 361-394. https://doi.org/10.1080/11956860.1998.11682468

Lafferty, K. D., \& Suchanek, T. H. (2016). Revisiting PaineâÁŹs 1966 sea star removal experiment, the most-cited empirical article in the American Naturalist. The American Naturalist, 188(4), 365-78. https://doi.org/10.1086/688045

Lowen, J., Innes, D., \& Thompson, R. (2013). Predator-induced defenses differ between sympatric Mytilus edulis and M. trossulus. Marine Ecology Progress Series, 475, 135-143. https://doi.org/10.3354/meps10106

Leignel, V., Stillman, J. H., Baringou, S., Thabet, R., \& Metais, I. (2014). Overview on the European green crab Carcinus spp.(Portunidae, Decapoda), one of the most famous marine invaders and ecotoxicological models. Environmental Science and Pollution Research, 21(15), 9129-9144.

Miron, G., Audet, D., Landry, T., \& Moriyasu, M. (2005). Predation potential of the invasive green crab (Carcinus maenas) and other common predators on commercial bivalve species found on Prince Edward Island. Journal of Shellfish Research, 24(2), 579-586.

Nunes, A. L., Orizaola, G., Laurila, A., \& Rebelo, R. (2014). Rapid evolution of constitutive and inducible defenses against an invasive predator. Ecology, 95(6), 1520-1530. https://doi.org/10.1890/13-1380.1

R Core Team. (2017). R: A language and environment for statistical computing. Vienna, Austria.

Reimer, O., \& Tedengren, M. (1997). PredatorâĂ Ǩinduced changes in byssal attachment, aggregation and migration in the blue mussel, Mytilus edulis. Marine and Freshwater Behaviour and Physiology, 30(4), 251-266. https://doi.org/10.1080/10236249709379029

Strauss, S. Y., Lau, J. A., \& Carroll, S. P. (2006). Evolutionary responses of natives to introduced species: What do introductions tell us about natural communities? Ecology Letters, 9(3), 357-374. https://doi.org/10.1111/j.1461-0248.2005.00874.x

Tollrian, R., \& Harvell, C. D. (1999). The ecology and evolution of inducible defenses. Princeton, NJ: Princeton University Press.

Trussell, G. C., \& Smith, L. D. (2000). Induced defenses in response to an invading crab predator: an explanation of historical and geographic phenotypic change. Proceedings of the National Academy of Sciences, 97(5), 2123-2127.

Via, S., \& Lande, R. (1985). Genotype-environment Interaction and the evolution of phenotypic plasticity. Evolution, 39(3), 505-522. https://doi.org/10.1111/j.1558-5646.1985.tb00391.x

Wickham, H. (2009). ggplot2: Elegant Graphics for Data Analysis. New York: Springer-Verlag 